\title{
$\mathrm{P}(\mathrm{VDF} / \mathrm{TrFE})$ 필름의 두께에 따른 인체 감지형 초전형 PIR 적외선 센서의 특성
}

권성열+

\section{Effect of P(VDF/TrFE) Film Thickness on the Characteristics of Pyroelectric Passive Infrared Ray Sensor for Human Body Detection}

\author{
Sung Yeol Kwon ${ }^{+}$
}

\begin{abstract}
A thick $25 \mu \mathrm{m}$ thickness poled $\mathrm{P}(\mathrm{VDF} / \mathrm{TrFE})$ film pyroelectric infrared ray sensor has been fabricated and then thin $1.6 \mu \mathrm{m}$ thickness $\mathrm{P}(\mathrm{VDF} / \mathrm{TrFE})$ film pyroelectric infrared ray sensor has been fabricated also. These thick and thin $\mathrm{P}(\mathrm{VDF} / \mathrm{TrFE})$ film pyroelectric infrared ray sensor was mounted in TO-5 housing to detect infrared light of $5.5 \sim 14 \mu \mathrm{m}$ wavelength for human body detecting with each other. The noise output voltage of the thick $\mathrm{P}(\mathrm{VDF} / \mathrm{TrFE})$ film pyroelectric infrared ray sensor were $380 \mathrm{mV}$ and NEP(noise equivalent power) is $3.95 \times 10^{-7} \mathrm{~W}$ which is the similar value with the commercial pyroelectric infrared ray sensor using ceramic materials as a sensing material. The NEP and specific detectivity $\mathrm{D}^{*}$ of the thin $\mathrm{P}(\mathrm{VDF} / \mathrm{TrFE})$ film pyroelectric infrared ray sensor were $2.13 \times 10^{-8} \mathrm{~W}$ and 9.37 $\times 106 \mathrm{~cm} / \mathrm{W}$ under emission energy of $13 \mu \mathrm{W} / \mathrm{cm}^{2}$ respectively. These result caused by lower thermal diffusion coefficient of a thin 1.6 $\mu \mathrm{m}$ thickness PVDF/TrFE film than the thick $25 \mu \mathrm{m}$ thickness poled $\mathrm{P}(\mathrm{VDF} / \mathrm{TrFE})$ film pyroelectric infrared ray sensor.
\end{abstract}

Keywords : PVDF, P(VDF/TrFE), Pyroelectric, Infrared, Ray, Thin film

\section{1. 서 론}

적외선 센서는 물체로부터 방사되는 에너지를 포토컨덕터 (Photoconductor)와 같이 직접적으로 흡수하여 광전자나 전하 커 리어 쌍을 형성하는 양자형과, 이를 열로 변환한 다음 발생하는 표 면전하의 변화를 측정하는 열형이 있다[1]. 현재 이러한 열형 초전 형 적외선 센서로 사용되고 있는 재료로는 TGS 단결정, $\mathrm{LiTaO}_{3}$, $\mathrm{PbTiO}_{3}, \mathrm{PZT}$ 와 PVDF 등이 있다[1-4]. 그 중 PVDF는 1969년 H. Kawai와 J. D. Bergmann에 의하여 압전효과 및 초전효과가 발 견된 이후로 이를 이용한 압력센서, 음향센서 및 초전형 적외선 센 서에 대한 많은 연구가 진행되고 있다[5, 15]. 또한 $\mathrm{PVDF}$ 와 전기 적인 특성은 비슷하지만 $\mathrm{P}(\mathrm{VDF} / \mathrm{TrFE})$ 필름은 큐리온도가 더 높 고, 더 낮은 유전상수, 낮은 열 확산계수를 가지고 있으므로 초전 형 적외선 센서 제작에 유리하다 $[6,7]$.

부경대학교 전기공학과(Department of Electrical Engineering, Pukyong National Unversity)

608-737, 부산광역시 남구 용소로 45, 부경대학교 전기공학과 가온관307호(Yongso-Ro 45, Pukyong National University, Nam-gu, Pusan 608737, Korea)

+Corresponding author: sungyeol@pknu.ac.kr

(Received : Jan 4, 2011, Revised : Mar 1, 2011, Accepted : Mar 14, 2011)
그러나 낮은 열 확산 계수를 가지는 초전형 필름의 제작이 어렵 고 이를 이용한 상용화된 센서의 종류가 많지 않다. 따라서 본 연 구에서는 분극 처리된 후막 $\mathrm{P}(\mathrm{VDF} / \mathrm{TrFE})$ 초전형 적외선 센서와 박막 $\mathrm{P}(\mathrm{VDF} / \mathrm{TrFE})$ 을 성막 시킨 후 초전성을 증가시키기 위한 분 극 처리하여 박막을 제작하고 이를 이용한 초전형 적외선 센서를 제작하여 $\mathrm{P}(\mathrm{VDF} / \mathrm{TrFE})$ 필름의 두께에 따른 초전형 적외선 센서 의 특성을 비교하였다. 제작된 센서는 모두 FET와 저항이 내장된 TO-5 패키지에 하우징하고 웰딩 하였다. 또한 상용센서와 같은 실험조건하에서 센서의 전압 출력, 잡음전압 출력, 전압감도, $\mathrm{NEP}$ (noise equivalent power) 및 specific detectivity $\mathrm{D}^{*}$ 를 측 정하여 $\mathrm{P}(\mathrm{VDF} / \mathrm{TrFE})$ 필름의 두께에 따른 초전형 적외선 센서의 성능지수를 비교하였다.

\section{2. 실험 방법}

\subsection{P(VDF/TrFE) 후막 적외선 센서 제작}

대량생산이 가능한 필름 형태의 $\mathrm{P}(\mathrm{VDF} / \mathrm{TrFE})$ 후막을 사용하여 적외선 센서를 제작하였다[8]. 적외선 센서에 사용된 $\mathrm{P}(\mathrm{VDF} / \mathrm{TrFE})$ 
후막의 비닐리딘 플루오라이드 $\left(\mathrm{VDF}, \mathrm{CH}_{2} \mathrm{CF}_{2}\right)$ 와 트리플루오르에 틸렌 $\left(\mathrm{TrFE}, \mathrm{CHFCF}_{2}\right)$ 의 질량비는 각각 $75 / 25$ 이다[9]. 분극 처리 된 $\mathrm{P}(\mathrm{VDF} / \mathrm{TrFE})$ 후막 필름의 두께는 $25 \mu \mathrm{m}$ 였고 제작한 소자의 크기는 가로 $\times$ 세로가 $3 \mathrm{~mm} \times 5 \mathrm{~mm}$ 였다. 필름에 상부 및 바닥 전 극 형성을 위하여 먼저 두께가 $50 \mu \mathrm{m}$ 의 몰리브덴판을 소자 전극 제작용 쉐도우 마스크로 제작하였다. 제작된 쉐도우 마스크를 사 용하여 먼저 하부 전극을 분극 처리된 $\mathrm{P}(\mathrm{VDF} / \mathrm{TrFE})$ 필름에 진공 증착 하였다. $\mathrm{P}(\mathrm{VDF} / \mathrm{TrFE})$ 의 녹는점 온도가 $160{ }^{\circ} \mathrm{C}$ 정도로 낮기 때문에 진공 증착시 가열되는 소스의 복사열이 $\mathrm{P}(\mathrm{VDF} / \mathrm{TrFE})$ 에 복사 전도되어 $\mathrm{P}(\mathrm{VDF} / \mathrm{TrFE})$ 필름이 녹아 내리거나 타버리는 현 상이 발생한다. 이러한 현상을 피하기 위해 진공 증착시 가열되는 소스와 $\mathrm{P}(\mathrm{VDF} / \mathrm{TrFE})$ 필름의 거리를 조절하여 가열되는 소스의 복사열이 $\mathrm{P}(\mathrm{VDF} / \mathrm{TrFE})$ 필름으로 복사 전도 되지 않도록 하였다. 같은 방법으로 상부전극을 진공 증착 하였으며 상 - 하부 전극으 로는 Al을 각각 $3000 \AA$ 과 $6000 \AA$ 의 두께로 진공 증착을 하였다.

전극을 증착한 후 소자를 주위의 잡음이나 간섭으로부터 차폐 하기 위해서 Fig. 1 에 보이는 바와 같이 상용센서용 TO-5 패키지 에 하우징을 하였다. TO- 5 패키지 내부는 FET와 면저항으로 구 성된 프리앰프(preamp.) 단이 내장되어 적외선 센서의 측정에서 가장 잡음에 민감한 부분인 센싱 소자와 $\mathrm{FET}$ 의 거리를 최소화하 고 외부 전기장으로부터 차폐가 되게 하였다.

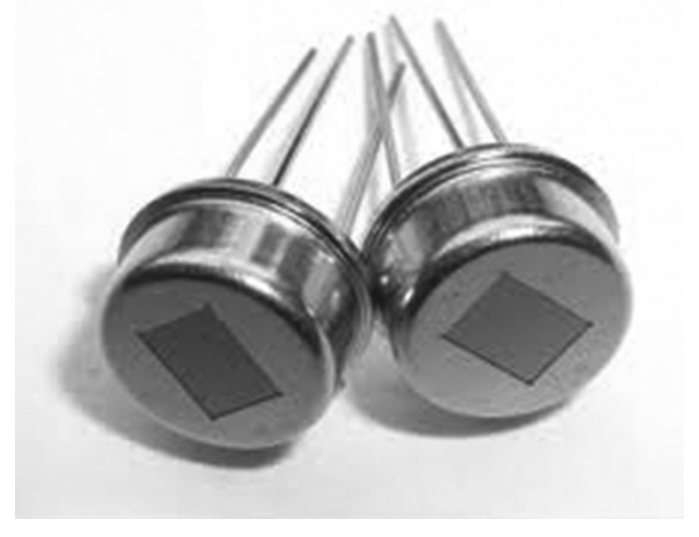

Fig. 1. Fabricated pyroelectric PIR infrared sensor.

\subsection{P(VDF/TrFE) 박막 적외선 센서 제작}

박막 초전형 적외선 센서의 기판은 열팽창계수가 크고 열차단 구조가 가능하며 프리앰프단의 FET의 제작이 가능한 실리콘 웨 이퍼를 사용하였다. 충분히 세척된 실리콘 웨이퍼에 습식 산화법 을 이용하여 $3000 \AA$ 의 두께로 $\mathrm{SiO}_{2}$ 층을 성장시켰다.

하부전극이 증착된 기판 위에 $65 / 35 \mathrm{wt} \%$ 의 $\mathrm{P}(\mathrm{VDF} / \mathrm{TrFE})$ 분 말과 2-butanone 용액을 $80{ }^{\circ} \mathrm{C}$ 의 온도에서 1 시간동안 용해시켜
제조한 $10 \mathrm{wt} \%$ 농도의 $\mathrm{P}(\mathrm{VDF} / \mathrm{TrFE})$ 용액으로 스핀코팅 방법을 통해 $\mathrm{P}(\mathrm{VDF} / \mathrm{TrFE})$ 박막을 성막 시켰다. 첫번째 단계에서는 500 $\mathrm{rpm}$ 과 2초, 그리고 두번째 단계에서는 $5000 \mathrm{rpm}$ 과 30 초의 스핀 코팅 방법으로 $1.6 \mu \mathrm{m}$ 의 박막을 제조하였다.

스핀코팅으로 제조된 박막의 내부에 남아있는 2-butanone 용 액의 증발과 건조, 그리고 막의 결함 제거 및 결정성 증가, 스트레 스 해소를 위해 24 시간 동안 상온에서 건조시킨 다음, $120{ }^{\circ} \mathrm{C}$ 에서 2시간 동안 열처리하였다[10]. 진공 증착시 가열되는 소스와 $\mathrm{P}(\mathrm{VDF} / \mathrm{TrFE})$ 막과의 거리를 조절하여 가열되는 소스의 복사열이 $\mathrm{P}(\mathrm{VDF} / \mathrm{TrFE})$ 막으로 복사 전도 되지 않도록 하여 상부 전극으로 $\mathrm{Al}$ 을 $3000 \AA$ 의 두께로 증착한 후 $\mathrm{P}(\mathrm{VDF} / \mathrm{TrFE})$ 막과 상부전극과 의 응착과 식각공정, 그리고 더욱 더 좋은 결정성 증가를 위하여 추가적인 열처리 과정을 실시하였다. 상부전극이 증착된 소자를 $150{ }^{\circ} \mathrm{C}$ 에서 10 분간 열처리하였다.

$\mathrm{P}(\mathrm{VDF} / \mathrm{TrFE})$ 박막은 $\mathrm{PVDF}$ 후막과는 달리 연신공정이 필요 없으며 분자쇄가 모두 trans형 사슬배좌로 구성되는 전기활성 강 유전 $\beta$ 상의 결정구조를 가진다[11]. 그러나 강유전 $\beta$ 상의 결정상 일지라도 C-F 에 의한 쌍극자들이 불규칙하게 배향되어 있기 때 문에 그 자체로는 압전성 및 초전성 재료로 사용하기에는 부적합 하다. 따라서 필름에 절연파괴가 일어나지 않을 정도의 높은 전계 를 걸어 주어 C-F 쌍극자를 한쪽 방향으로 배향 시켜 주는 추가적 인 분극 공정을 필요로 한다[11]. $\mathrm{P}(\mathrm{VDF} / \mathrm{TrFE})$ 박막의 분극공정 으로는 열분극, 코로나분극, 전자빔을 이용한 방법 등[11]이 있으 나 본 실험에서는 상온에서 $\mathrm{DC}$ 전압을 이용한 열분극 공정을 행 하였다. 최적조건의 분극공정을 실현하기 위하여 실험한 여러 가 지 조건의 분극공정 조건을 Table. 1 과 Fig. 2 에 나타내었다.

분극 중에 발생할 수 있는 막의 브레이크다운 현상을 감소시키 면서 최대 전계를 막에 가해 주기 위해 막에 $20 \mathrm{MV} / \mathrm{m}$ 부터 $100 \mathrm{MV}$ $/ \mathrm{m}$ 까지 전압을 단계적으로 $20 \mathrm{MV} / \mathrm{m}$ 씩 증가시키면서 분극을 행하 였다. 각각의 분극 시간은 8 분이었으며 각 단계 사이에 분극에 의 한 스트레스 제거를 위해 4 분씩 상하전극을 서로 단락 시켰다. 이 방법으로 전기적인 브레이크다운은 저전압에서부터 만들어진 분 극에 의해 감소하고 열적인 브레이크다운은 제한된 전류와 전도 성의 감소로 인해 줄어들게 된다. Fig. 2 는 본 실험에서 행한 분극 방법을 전계와 시간에 따른 그래프로 나타내었다. 분극 공정후 소 자를 주위의 잡음이나 간섭으로부터 차폐하고 $\mathrm{P}(\mathrm{VDF} / \mathrm{TrFE})$ 필름 의 두께에 따른 적외선 센서의 특성 비교를 위해 후막 센서와 같은 사양의 TO-5 패키지에 하우징을 하였다.

Table. 1. Poling conditions for P(VDF/TrFE) film

\begin{tabular}{ccc}
\hline poling time & short time & status \\
\hline $10 \mathrm{~min}$. & no & breakdown at $40 \mathrm{MV} / \mathrm{m}$ \\
\hline $8 \mathrm{~min}$. & $2 \mathrm{~min}$. & breakdown at $40 \mathrm{MV} / \mathrm{m}$ \\
\hline $8 \mathrm{~min}$. & $4 \mathrm{~min}$. & breakdown at $110 \mathrm{MV} / \mathrm{m}$ \\
\hline $8 \mathrm{~min}$. & $8 \mathrm{~min}$. & breakdown at $110 \mathrm{MV} / \mathrm{m} 110 \mathrm{MV} / \mathrm{m}$ \\
\hline
\end{tabular}




\section{3. 결과 및 고찰}

\subsection{P(VDF/TrFE) 후막 적외선 센서의 특성}

제작된 초전형 적외선 센서의 신호출력 및 잡음 측정은 Table. 2 에 기재된 환경과 조건에서 측정되었다.

측정시에는 두 상부전극 중 한 개에 대하여 적외선을 차단한 후 측정을 하였다. 여기서 두 상부전극 중 한 개의 전극에 대하여 적 외선을 차단하고 측정한 이유는 본 실험에서 제작된 소자의 경우 적외선이 각각의 전극에 동일하게 조사 될 경우 각각의 소자에 유 기되는 초전 전압의 절대치가 서로 같아 압전효과에 의한 것과 마 찬가지로 상쇄되기 때문이다. 제작된 소자는 $\mathrm{FET}$ 와 저항에 연결 하여 출력과 잡음을 측정하였으며 인체 검지용으로 사용하기 위 하여 $5.5 \sim 14 \mu \mathrm{m}$ 의 적외선 필터가 부착된 TO- 5 에 하우징 하였 다. 제작된 소자를 $420^{\circ} \mathrm{K}$ 의 열원과 $1 \mathrm{~Hz}$ 의 주파수로 열원으로부 터 발생하는 적외선에 따라 변화하는 전압의 변화를 $72.5 \mathrm{~dB}$ 로 증 폭하여 측정하였고 잡음의 측정은 완전히 차폐된 용기 안에서 파 이로 일렉트로미터(pyroelectrometer)를 이용하여 $72.5 \mathrm{~dB}$ 로 증 폭 하여 측정하였다.

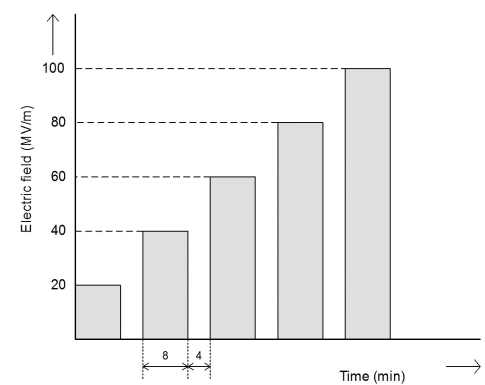

Fig. 2. Poling conditions for $\mathrm{P}(\mathrm{VDF} / \mathrm{TrFE})$ film.

Table 2. Signal and noise output measuring conditions

\begin{tabular}{|c|c|c|}
\hline \multicolumn{2}{|r|}{ poling time } & status \\
\hline \multicolumn{2}{|c|}{ Ambient temperature } & $25^{\circ}$ \\
\hline \multicolumn{2}{|c|}{ Black body temperature } & $420^{\circ} \mathrm{K}$ \\
\hline \multicolumn{2}{|c|}{ Aperture of black body } & $\Phi 40$ \\
\hline \multicolumn{2}{|c|}{ Emission of infrared energy } & $13 \mu \mathrm{Wcm}^{2}$ \\
\hline \multicolumn{2}{|c|}{ Chopping frequency } & $1.0 \mathrm{~Hz}$ \\
\hline \multirow{2}{*}{ Amp. gain } & signal & $72.5 \mathrm{~dB}(1 \mathrm{~Hz})$ \\
\hline & noise & $72.5 \mathrm{~dB}$ \\
\hline \multicolumn{2}{|r|}{$3 \mathrm{~dB}$ bandwidth } & $0.4 \sim 4.5 \mathrm{~Hz}$ \\
\hline \multicolumn{2}{|c|}{ Stabilization time(noise) } & $3 \mathrm{~min}$ \\
\hline \multicolumn{2}{|c|}{ Measuring time(noise) } & $20 \mathrm{sec}$ \\
\hline
\end{tabular}

용기 안에서 파이로 일렉트로미터(pyroelectrometer)를 이용하 여 $72.5 \mathrm{~dB}$ 로 증폭 하여 측정하였다. 측정된 값은 신호의 전압 출 력이 $0.5 \mathrm{~V}$, 잡음 전압 출력이 $380 \mathrm{mV}$ 로 측정되었다. 제작된 소자 는 적외선원 $13 \times 10^{-6} \mathrm{~W} / \mathrm{cm}^{2}$ 과 초핑 주파수 $1 \mathrm{~Hz}$ 에 대해 9.62 $\times 10^{5} \mathrm{~V} / \mathrm{W}$ 의 전압감도를 나타내었으며 $\mathrm{NEP}$ (noise equivalent power)는 $3.95 \times 10^{-7} \mathrm{~W}$, 그리고 specific detectivity $\mathrm{D}^{*}$ 는 5.06 $\times 10^{5} \mathrm{~cm} / \mathrm{W}$ 를 각각 나타내었다.

\section{2 $\mathrm{P}(\mathrm{VDF} / \mathrm{TrFE})$ 박막 적외선 센서의 특성}

제작된 박막 센서 소자는 분극 처리된 후막 $\mathrm{P}(\mathrm{VDF} / \mathrm{TrFE})$ 필름 적외선 센서와 같은 조건에서 측정되었다. 측정된 값은 신호의 전 압 출력이 $1.315 \mathrm{~V}$, 잡음 전압 출력이 $215.7 \mathrm{mV}$ 로 측정되었다. 제 작된 소자는 적외선원 $13 \times 10^{-6} \mathrm{~W} / \mathrm{cm}^{2}$ 과 초핑 주파수 $1 \mathrm{~Hz}$ 에 대해 $1.01 \times 10^{7} \mathrm{~V} / \mathrm{W}$ 의 높은 전압감도를 나타내었으며 NEP는 $2.13 \times 10^{-8} \mathrm{~W}$, 그리고 $\mathrm{D}^{*}$ 는 $9.37 \times 10^{6} \mathrm{~cm} / \mathrm{W}$ 를 나타내었다.

\section{4. 결 론}

$\mathrm{P}(\mathrm{VDF} / \mathrm{TrFE})$ 필름의 두께에 따른 초전형 적외선 센서의 성능 지수를 비교 하기 위하여 $25 \mu \mathrm{m}$ 두께의 $\mathrm{P}(\mathrm{VDF} / \mathrm{TrFE})$ 후막 초전 형 적외선 센서와 $1.6 \mu \mathrm{m}$ 두께의 $\mathrm{P}(\mathrm{VDF} / \mathrm{TrFE})$ 박막 초전형 적외 선 센서를 제작하였다. 후막 초전형 적외선 센서의 감지부분은 대 량생산이 가능한 필름 형태의 분극 처리된 $\mathrm{P}(\mathrm{VDF} / \mathrm{TrFE})$ 를 사용 하였고, 박막 초전형 적외선 센서의 감지부분은 $65 / 35 \mathrm{wt} \%$ 의 $\mathrm{P}(\mathrm{VDF} / \mathrm{TrFE})$ 를 2-butanone 용액에 용해시켜 제조한 $10 \mathrm{wt} \%$ 용액으로 스핀코팅 방법을 통해 $\mathrm{P}(\mathrm{VDF} / \mathrm{TrFE})$ 박막을 성막 후 박 막의 압전성을 줄이고 초전성을 증가시키기 위해 분극 처리후 센 서 제작을 하였다. Table. 3은 $\mathrm{P}(\mathrm{VDF} / \mathrm{TrFE})$ 후막 및 박막 초전형 적외선 센서의 성능을 나타낸 것이다.

제작한 $25 \mu \mathrm{m}$ 두께의 후막 초전형 적외선 센서는 잡음이 380 $\mathrm{mV}$ 로 다소 높게 나왔으며, $\mathrm{NEP}$ 는 $3.95 \times 10^{-7} \mathrm{~W}$ 로서 다른 상 용 세라믹 초전형 적외선 센서와 다소 비슷한 편이었다[12-14]. $1.6 \mu \mathrm{m}$ 두께의 박막 초전형 적외선 센서는 후막 초전형 센서의 전 압감도에 비해 두단위 이상의 우수한 감도를 나타내었으며, NEP 와 $\mathrm{D}^{*}$ 도 한단위 이상의 우수한 성능을 나타내었다. 이는 $1.6 \mu \mathrm{m}$ 두께의 박막 $\mathrm{P}(\mathrm{VDF} / \mathrm{TrFE})$ 필름의 낮은 열확산 계수에 기인하는 것으로서 보다 얇은 박막 초전형 적외선 센서가 이러한 열형 적외 선 센서의 성능을 향상하는 것으로 사료되며 이러한 실험결과로 서 박막 $\mathrm{P}(\mathrm{VDF} / \mathrm{TrFE})$ 필름을 사용한 초전형 적외선 센서의 제작 및 상용화가 가능하리라 판단된다.

Table 3. Comparison of sensor characteristics

\begin{tabular}{c|c|c}
\hline & $25 \mu \mathrm{m}$ film sensor & $1.6 \mu \mathrm{m}$ film sensor \\
\hline 신호전압출력 & $0.500 \mathrm{~V}$ & $1.315 \mathrm{~V}$ \\
\hline 잡음전압출력 & $380 \mathrm{mV}$ & $215.7 \mathrm{mV}$ \\
\hline 전압감도 & $9.62 \times 10^{5} \mathrm{~V} / \mathrm{W}$ & $1.01 \times 10^{7} \mathrm{~V} / \mathrm{W}$ \\
\hline $\mathrm{NEP}$ & $3.95 \times 10^{-7} \mathrm{~W}$ & $2.13 \times 10^{-8} \mathrm{~W}$ \\
\hline $\mathrm{D}^{*}$ & $5.06 \times 10^{5} \mathrm{~cm} / \mathrm{W}$ & $9.37 \times 10^{6} \mathrm{~cm} / \mathrm{W}$ \\
\hline \multicolumn{2}{|r}{}
\end{tabular}




\section{REFERENCES}

[1] R. W. Whatmore, "Pyroelectric devices and materials", Rep. Prog. Phys., vol. 49, pp. 1335-1386, 1986.

[2] C. Lucat, F. menil, and R. Von Der Muhll, "Thick-film densification for pyroelectric sensors", Meas. Sci. Technol., vol. 8, pp. 38-41, 1997.

[3] C. C. Chang and C. S. Tang, "An integrated pyroelectric infrared sensor with a PZT thin film", Sensors and Actuators A. vol. 65, pp. 171-174, 1998.

[4] W. Ruppel, "Pyroelectric sensor arrays on silicon", Sensors and Actuators A. vol. 31, pp. 225-228, 1992.

[5] P. C. A. Hammes and P. P. L. Regtien, "An intergrated infrared sensor using the pyroelectric polymer PVDF", Sensors and Actuators A. vol. 32, pp. 396-402, 1992.

[6] R. Kohler, N. Neumann, and G. Hofmann, "Pyroelectric single-element and linear-array sensors based on P(VDF/TrFE) thin films", Sensors and Actuators A., vol. 45, pp. 209-218, 1994.

[7] G. T. Davis, J. E. Mckinney, M. G.Broadhurst, and S. C. Roth, "Electric-field-induced phase changes in poly(vinylidene fluoride)", J. Appl. Phys., vol. 49, pp. 4988-5002, 1978.

[8] Sung Yeol Kwon and Ki Wan Kim, "Fabrication and characteristics of pyroelectric infrared sensors using P(VDF/TrFE) film", J. Kor. Sensors Soc., vol. 8, no. 3, pp. 226-231, 1999.
[9] D. K. Das-Gupta, Ferroelectric polymers and ceramicpolymer composites, Trans. Tech. Pub. Switzerland, 1994.

[10] Sung Yeol Kwon, "Fabrication and characteristics of pyroelectric infrared IR sensors using $\mathrm{PbTiO}_{3}$ /P(VDF/TrFE) thin films", Kyungpook National University, Ph.D., Thesis, 2000.

[11] J. A. Giacometti, J. Sinezio, C. Campos, N. Alves, and M. M Costa, "The electric behavior of PVDF and P(VDF/TrFE) during corona poling," IEEE 1990 Annual Report Conference on Electrical Insulation and Dielectric Phenomena, pp. 77-82, 1990.

[12] Jin Sik Kim, "Study of dielectric, pyroelectric and piezoelectric characteristics PVDF for sensor", Inha University, Ph. D., Thesis, 1992.

[13] Young Eil Kim and Yong Rae Roh, "Fabrication of pyroelectric infrared sensors using PLT thin plates", $J$. Kor. Sensors Soc., vol. 5, no. 1, pp. 226-231, 1999.

[14] Young Eil Kim, Yong Rae Rohand, and Sie Young Choi, "Fabrication of pyroelectric IR sensors with PLT thin plates compensating for piezoelectric effect", J. Kor. Sensors Soc., vol. 6, no. 1, pp. 1-5, 1997.

[15] A. Odon, "Voltage response of pyroelectric PVDF detector to pulse source of optical radiation", Meas. Sci. Review, vol. 5, Sec. 3, pp. 55-58, 2005.

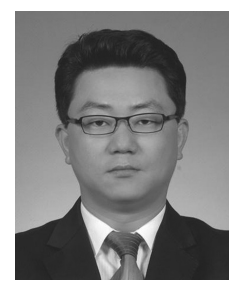

\section{권 성 열(Sung Yeol Kwon)}

- 2000년 경북대학교 대학원 센서공학과 (공학박사)

• 2007년 현재 부경대학교 전기공학과 부교수 